\title{
EDITORIALS
}

\section{Psychology in relation to psychiatry}

'Just as physiology is basic to physical medicine, so might psychology be considered the basic science of psychiatry.' This rather large claim was made by the writer of a leading article in a recent issue of the British Medical Journal (1972) on the theme of research in psychiatry. As it poses something of a challenge, at all events to psychologists, it might seem to merit some examination. The question is not so much 'Is it true?' as 'Could it become true?'

It is not, of course, the first time that such a claim has been made on behalf of psychology. Yet to the present-day psychiatrist, basic sciences such as biochemistry, pharmacology, and genetics might seem prima facie to have more immediate relevance to his subject. Once, indeed, the fashionable basic science was neuropathology, and to Wilhelm Griesinger and his disciples in mid-19th century Germany, mental disorders were but the expression of disease of the brain. Their slogan was Psychiatrie ohne Psychologie. But it soon became apparent that not all diseases of the brain produce mental symptoms and not all mental symptoms are due to brain lesions. Hence the stage was set for a re-entry of psychology into the psychiatric world.

When in time it came, the reaction to 'brain psychiatry' was, of course, altogether excessive. For Freud, there were only two sciences: psychology, pure and applied, and natural science. While conceding that the methods of science had served medicine-including parts of psychiatry-well, Freud had no doubt that the major issues of neurosis, and perhaps even of psychosis too, would find solution only through the applications of psychology. Indeed his slogan might well have been Psychiatrie ohne Neuropathologie. Since Freud's death, the limitations of psychoanalysis have become very apparent, though many of the ideas that emerged from his work continue to agitate psychiatric thought and to find application, pure or diluted, in the various brands of psychotherapy. To this extent, then, psychology of a kind is already basic to some areas of psychiatry and seems extremely likely to remain so.

But it is plainly not psychoanalysis that the writer of the leading article referred to above has in mind. 'In recent years', he continues, 'psychology has made great advances in establishing a solid scientific foundation by rigorous experimentation.' It is, then, on behalf of experimental psychology (which, incidentally, Freud dismissed as trivial and irrelevant to clinical psychiatry) that he advances his claim. Before trying to assess its relevance, actual or potential, to progress in psychiatry, it is perhaps advisable to take a brief look at its origins, development, and present-day standing.

As an academic discipline, experimental psychology was born in Germany about 100 years ago. Its midwives were G. T. Fechner, a physicist with a decided inclination towards philosophy and mysticism, $\mathrm{H}$. von Helmholtz, the founder of modern sensory physiology, and W. Wundt, a physiologist who turned to psychology and established the first formal psychological laboratory at Leipzig in 1879. By and large, the aim of the new science was to develop quantitative techniques to throw light on the nature and course of conscious processes. Not surprisingly, its main successes lay in the fields of psychophysics and the special senses, in which it extended its already close links with sensory physiology. Its application to higher mental processes, such as memory or thinking, were somewhat less happy, largely due to a passionate and indeed at times almost comic dependence on introspection. None the less, Kraepelin, who had studied with Wundt, made some attempt to apply the methods of experimental psychology to issues in psychiatry, though it cannot be said that the outcome was particularly auspicious. To most clinical psychiatrists, the new 'brass instrument' psychology, as it was disparagingly called, was too arid, too fractional, and too academic to have effective application to psychiatric reality.

Wundt's experimental psychology was imported to America by a number of his erstwhile students, 
of whom the best remembered is perhaps the Englishman, E. B. Titchener, who taught for many years at Cornell. But here it found itself on distinctly alien soil. Psychology in America grew up with a strong biological and evolutionary background and a very considerable concern for the study of development and of individual differences in mental capacity. Indeed after a few years little was to remain of Wundtian psychology other than the idea of experiment itself, and even this was soon grafted on to sturdier native roots.

The tension between the German and American attitudes towards psychology ultimately exploded in the Behaviourist revolution, which from 1916 onwards aimed to deprive psychology of its traditional subject matter of consciousness and to redefine it as a wholly objective science of behaviour. Behaviourism, which owes its existence largely to two men-J. B. Watson and Karl S. Lashleytogether with a favourable Zeitgeist, soon established itself as the accepted academic psychology in the United States and is the precursor of the 'Behavioural Sciences' as we know them today. Although a brash and naive philosophy, Behaviourism did much to rescue psychology from the pitfalls of pseudo-scientific introspectionism and to secure its foundations as a biological science. The physiological groundwork was firmly laid by K. S. Lashley, the first to study quantitatively the effects of brain lesions on learning and preformance in the rat and monkey. The developmental studies undertaken by such men as Leonard Carmichael and Arnold Gesell laid the foundations of what is nowadays known as behavioural genetics. In the study of conditioning and learning, the work of $\mathrm{C}$. $\mathrm{L}$. Hull, E. C. Tolman, and B. F. Skinner brought new techniques into the study of animal behaviour and underlined the importance of more sophisticated methodology and theory. Although the almost exclusive concern with animal learning and behaviour theory seemed to some excessive (Piaget dubbed it the 'American disease'), there can be no doubt that Behaviourism did much to emancipate psychology from its philosophical antecedents and to create at least the simulacrum of an objective science.

In the years since the end of the second world war, psychology has largely outgrown the narrowly Behaviourist standpoint and now sees little virtue in conditioned reflexes or the taboo on consciousness. By and large, two lines of development have emerged. The first, originating in Lashley's work, seeks to join forces with the emerging neurosciences in order to mount a concerted attack on the brain envisaged as the instrument of behaviour. The second, which represents in some respects a reversion to the older psychology of conscious processes, seeks fresh inspiration from the development of computer technology and communication theory. The first approach has come to be known as physiological psychology, and remains essentially behaviouristic in method. The second is sometimes called cognitive psychology and accepts in principle the existence of conscious events, though their explanation is for the most part sought within the broader framework of cybernetics.

It is perhaps in physiological psychology, seen not so much in isolation as in relation to neurophysiology, neurochemistry, pharmacology, and endocrinology, that one might see a possible basis for a rational psychiatry. The general field has been well delimited in a number of recent texts (Thompson, 1967; Butter, 1968; Milner, 1970) and it is unnecessary to review it in any detail. As examples of the work psychologists are doing which may come to possess importance for psychiatry are the studies inaugurated by Olds and Milner (1954) on intracranial self-stimulation and its relation to hypothalamic and limbic mechanisms; the work of Miller (1969) and his associates on the operant conditioning of visceral responses; and the many recent studies of the behavioural effects of fear and stress in animals, ably reviewed by Gray (1971). One should also add the long series of studies on the effects of brain lesions on behaviour in primates, which K. H. Pribram in America and L. Weiskrantz in this country have done so much to foster (Weiskrantz, 1964). While premature generalization of the results of animal experiment to man-as we have recently witnessed in the introduction of certain forms of psychosurgery and behaviour therapy-is to be deplored, it seems likely that our advancing understanding of the brain as the instrument of behaviour can hardly fail to have implications for psychological medicine. These, however, should be regarded as essentially long-term and there is as yet little in contemporary physiological psychology which might seem of direct application to psychiatric practice. 
Cognitive psychology has the advantage of being wholly concerned with human activity, and might, therefore, seem closer to medical interests. Indeed, several contemporary aspects of this field have been surveyed in a recent issue of the British Medical Bulletin (Summerfield, 1971), which was the subject of an enthusiastic leading article in the British Medical Journal (1971). The writer commented that the appearance of this issue ... marks the steady progress which has been achieved with such problems as attention, memory, learning, the use of language and the acquisition of skills'. He further urged that its appearance will help to correct the views of those who still doubt the place of psychology in the medical curriculum. Yet this compilation contains very little directly relevant to psychiatry and seems rather to reinforce the remark made by the writer of the B.M.J. leading article cited at the start of this Editorial that the findings of contemporary psychology seem more relevant to neurology than to psychiatry. It is, therefore, pertinent to inquire in what this relevance consists and whether a comparable relevance to psychiatric issues can be anticipated.

Application of the methods of experimental psychology to neurological issues goes back at least to the first world war, when Gelb and Goldstein, Poppelreuter and Isserlin in Germany, and Henry Head in Great Britain, attempted to introduce more systematic techniques for the assessment of the psychological sequelae of focal brain wounds. During and after the second world war, techniques of this kind were further developed with the addition of more adequate control studies and statistical evaluation of the data. The earlier studies of Teuber and his associates (Teuber, Battersby, and Bender, 1960; Semmes, Weinstein, Ghent, and Teuber, 1960) and the more recent report of Newcombe (1969), based on material studied at the Head Injuries Bureau at Oxford, provide good examples of the scientific promise of such work. Other examples of the application of psychological techniques to the analysis of a variety of problems in clinical neurology are to be found in the issue of the British Medical Bulletin mentioned above. They include aphasia, neurological disorders of memory, and interhemispheric differences in the localization of psychological function in man.

By and large, breakdown of high-level neurological function, as expressed in disorder of perception, memory, purposive action, and speech, is relatively amenable to experimental analysis. Psychiatric illness, on the other hand, presents for the most part in disorder of emotion, personality, and conduct, and is consequently less open to experimental study. Indeed, almost the only field of psychiatry in which psychological experiment has hitherto proved itself fruitful is the analysis of cognitive deficits in subnormal and autistic children (O'Connor and Hermelin, 1963; Hermelin and O'Connor, 1970). True, there have been many attempts to mount an experimental attack on the problems of schizophrenia, in particular the derangements of attention and language that loom so large in this disorder, but, so far, alas, there has been no sign of a breakthrough. It might be a wiser research strategy to defer attempts to subject the main psychiatric disorders to psychological analysis until neurophysiological, neurochemical, and pharmacological advances have made it possible to ask more clear-cut questions. To give but one example, there are already indications that minimal temporal lobe dysfunction as indicated by EEG criteria may be causally linked with the incidence of emotional and behaviour disorders in young people. In such cases, it is not uncommon to find minimal memory or speech disturbances on careful psychological examination.

One contemporary approach to psychological issues which to some extent embodies both the physiological and the cognitive standpoints is that represented in the work of Roger Sperry and his associates at the California Institute of Technology. This is the 'split-brain' technique, developed first by Myers and Sperry in experimental work with cats and monkeys and later extended to human beings. In 1962, Bogen and Vogel reported the first case of commissurotomy for the relief of intractable epilepsy and an appreciable number of such patients are now available. The majority have been studied extremely thoroughly by Sperry and his colleagues, and as a result of their work the inter-relations of the two hemispheres in cognitive activities are gradually becoming clearer (Sperry, Gazzaniga, and Bogen, 1969). Important studies of perception (Gazzaniga, Bogen, and Sperry, 1965), language (Gazzaniga and Sperry, 1967), and praxis (Gazzaniga, Bogen, and Sperry, 1967) have already appeared and further studies are in preparation. In particular, brief simultaneous presentation of visual material to the two disconnected hemispheres has revealed that perceptual events of a 
high order of complexity may occur concurrently but independently in the two hemispheres (Levy, Trevarthen, and Sperry, 1972). This finding provides belated justification for the speculations put forward as long ago as 1844 by Dr. A. L. Wigan, a noteworthy psychiatrist of his day, in a curious work entitled The Duality of the Mind. While there has as yet been little psychiatric study of 'splitbrain' patients, their implications for medical psychology might well prove considerable. For example, the whole question of amnesia and dissociation might come to be seen in an entirely new light in relation to the anatomy of the brain.

It may seem odd that an article on psychology in relation to psychiatry should have so far made no mention of the area of psychological work most familiar to clinical psychiatrists-namely, psychometric testing. The reason is that psychometric methods have evolved not from traditional experimental psychology but from the highly practical efforts by Binet and his successors to develop improved methods of detecting and assessing educationally subnormal children. From this work arose the concepts of mental age and IQ which have had so powerful, if in some respects baleful, an influence on contemporary social and educational thought. The psychometric approach was later adapted to the assessment of adult mental capacity, again largely to meet practical needs, in particular personnel selection in the U.S. Armed Services in the first world war. In the clinical field, it found application mainly in Wechsler's well-known adult intelligence scales, first published in 1939 and since widely used by clinical psychologists in this country (Wechsler, 1958). While the Wechsler and allied methods have considerable practical utility, especially in regard to the assessment of degrees of subnormality and of mental deterioration in relation to age, it should be clearly understood that psychometric measurement is in no sense akin to physical measurement. The criteria of ability employed in the construction of intelligence tests are very largely arbitrary and the extent to which they may be held to assess inborn mental capacity remains highly controversial. Even Professor $\mathbf{H}$. J. Eysenck, whose loyalty to psychometric method is unquestioned, has lamented its separation from the general body of experimental psychology and strongly advocates a more genuinely experimental approach to psychometric issues (Eysenck, 1967). As the present writer has remarked elsewhere: 'Intelligence testing is a technology whose theoretical foundations are distinctly insecure' (Zangwill, 1963).

In conclusion, one may hazard the view that there is not and never will be one scientific discipline basic to psychiatry. Indeed, it seems likely that the attempt periodically made to invest psychology with this distinction reflects not so much a genuine belief in its powers or promise but rather the aftermath of a now largely outmoded dualism of body and mind. Psychiatry, as the study and treatment of mental disorder, should be founded on psychology, the science of the mind. Or so runs the traditional argument. But psychiatry now recognizes the need to look increasingly to physical dysfunction for an understanding of its problems and even the concept of psychogenesis in relation to the neuroses is undergoing revision (Lewis, 1972). Equally, psychology no longer aspires to be the science of mind and is content to regard itself simply as one of the many component disciplines of which modern biology is composed. Psychiatry in the future will no doubt lean heavily on both the biological and the social sciences, which should be regarded as its twin pillars. It should not seek its inspiration from one alone of their component disciplines.

O. L. ZANGWILL

\section{REFERENCES}

Bogen, J. E., and Vogel, P. J. (1962). Cerebral commissurotomy in man: Preliminary case report. Bulletin of the Los Angeles Neurological Society, 27, 169-172.

British Medical Journal. (1972). Leading article: Research in psychiatry. 2, 61-62.

British Medical Journal. (1971). Leading article: Psychology as science. 4,68

Butter, C. M. (1968). Neuropsychology: The Study of Brain and Behavior. Brooks/Cole: Belmont, California.

Eysenck, H. J. (1967). Intelligence assessment: a theoretical and experimental approach. British Journal of Educational Psychology, 37, 81-98. Reprinted in H. J. Butcher and D. E. Lomax (Eds.). Readings in Human Imtelligence, pp. 20-39. Methuen: London. 1972.

Gazzaniga, M. S., Bogen, J. E., and Sperry, R. W. (1965). Observations on visual perception after disconnexion of the cerebral hemispheres in man. Brain. 88, 221-236.

Gazzaniga, M. S., Bogen, J. E. and Sperry, R. W. (1967). Dyspraxia following division of the cerebral commissures. Archives of Neurology, 16, 606-612. 
Gazaniga, M. S., and Sperry, R. W. (1967). Language after section of the cerebral commissures. Brain, 90, $131-148$.

Gray, J. A. (1971). The Psycholugy of Fear and Stress. Weidenfeld and Nicholson: London.

Hermelin, B., and $O^{\circ}$ Connor, N. (1970). Psychological Experiments with Autistic Children. Pergamon: Oxford.

Levy, J.. Trevarthen, C., and Sperry, R. W. (1972). Perception of bilateral chimeric figures following hemispheric deconnexion. Brain, 95, 61-78.

Lewis, A. (1972). 'Psychogenic': a word and its mutations. Psychological Medicine, 2, 209-215.

Miller, N. E. (1969). Learning of visceral and glandular responses. Science, 163, 434-445.

Milner, P. (1970). Physiological Psychology. Holt: New York.

Newcombe, F. (1969). Missile Wounds of the Brain. Oxford University Press: London.

O'Connor, N., and Hermelin, B. (1963). Speech and Thought in Severe Subnormality. Pergamon: Oxford

Olds, J., and Milner, P. (1954). Positive reinforcement produced by electrical stimulation of septal arca and other regions of rat brain. Journal of Comparative Physiology and Psychology, 47, 419-427.

Semmes, J., Weinstein, S., Ghent, L., and Teuber, H.-L. (1960). Somotosensory Changes After Penetrating Brain
Wounds in Man. Commonwcalth Fund. Harvard University Press: Cambridge, Mass.

Sperry, R. W., Gazzaniga, M. S., and Bogen, J. E. (1969). Interhemispheric relationships: the neocortical commissures; syndromes of hemisphere disconnection. In Handbook of Clinical Neurulogy. Edited by P. J. Vinken and G. W. Bruyn. 4, 273-290. North Holland: Amsterdam.

Summerficld, A. (Editor). (1971). Cognitive psychology. British Medical Bulletin, 27, No. 3.

Teuber, H.-I., Battersby, W. S., and Bender, M. B. (1960). Visual Field Defects After Penetrating Missile Wounds of the Brain. Commonwealth Fund. Harvard University Press: Cambridge, Mass.

Thompson, R. F. (1967). Foundations of Physiological Psychology. Harper: New York.

Wechsler, D. (1958). The Measurement and Appraisal of Adult Imtelligence, 4 th edn. Bailliere, Tindall, and Cox: London.

Weiskrantz, L. (1964). Neurological studies and animal behaviour. British Medical Bulletin, 20, 49-53.

Wigan, A. L. (1844). The Duality of the Mind. Longman: London.

Zangwill, O. L. (1963). An Introduction to Modern Psychology. Methuen: London.

\section{Psychological studies in subnormality}

A summary of previous work concerning learning in subnormal children (O'Connor, 1958) drew on a review by McPherson (1948) which mentioned 16 studies. These led McPherson to conclude, along with Gardner (1945), that motivation must be maximal for the effective study of learning and performance, and that, in motor learning, neither starting level nor mental age was a good guide to the ultimate level of achievement. These few experiments and their modest conclusions were not widely extended during the intervening decade until the review quoted. Studies of unskilled motor performance and motivation were noted, and also a limited number of investigations on word learning and the phenomenon of transposition. These were along the same lines as earlier, classical studies, but there were a few in addition, concerned with reaction time and its relation to intelligence. Such experimental work was limited to a few studies and gave no hint of the renaissance of work in this area which was to follow in the next decade. However, the second edition of the review (1965) was extended by several pages to cover the already considerable expansion of experimental studies. In these pages the work of Clarke and Blakemore (1961) on transfer, Lyle (1959) and Mein and O'Connor (1960) on language, Spitz (1963) on perception, House and Zeaman (1958) on discrimination, and O'Connor and Hermelin (1963a) on learning were listed among others. The general trend of these studies was to break with the tradition of psychometrics and factor classification and to examine psychological processes experimentally. Cognitive structure involving perception, learning, coding, and recall became the centre of interest in the place of intelligence and factor structure.

This was the beginning of a movement which has led since to many experimental studies of shortterm memory, long-term memory, cross-modal transfer, visual discrimination, language usage, and attention. Such experimental investigations as those of Ellis (1963), Zeaman and House (1963), O'Connor and Hermelin (1963b), Spitz (1963), Woodward (1963), and Luria (1961) have usually had two major intentions. They were aimed at adapting the techniques of experimental psychology to the study of process deficit in the subnormal child and at relating normal to abnormal development. Other investigators have applied the resulting knowledge to the rehabilitation and treatment of all grades of subnormal children, and this extensive and useful work has been an important element in motivating the analysis of the psychological assets and deficits of the subnormal individual. 